\title{
EFFECT OF WORKING FLUID ON SELECTION OF GAS TURBINE CYCLE CONFIGURATION FOR GEN-IV NUCLEAR POWER PLANT SYSTEM
}

\author{
Emmanuel O. Osigwe \\ Cranfield University \\ Cranfield, Bedfordshire, United Kingdom
}

\author{
Arnold Gad-Briggs \\ Cranfield University \& EGB Engineering \\ United Kingdom
}

\author{
Pericles Pilidis \\ Cranfield University \\ Cranfield, Bedfordshire, United \\ Kingdom
}

\author{
Theoklis Nikolaidis \\ Cranfield University \\ Cranfield, Bedfordshire, United \\ Kingdom
}

\author{
Suresh Sampath \\ Cranfield University \\ Cranfield, Bedfordshire, United \\ Kingdom
}

Keywords: Working Fluid, Closed-Cycle Gas Turbine, Cycle Performance, Technology Readiness, Generation IV Nuclear Reactors

\begin{abstract}
The cycle configuration of the energy conversion system in a nuclear power plant tends to have a governing effect on the overall performance and acquisition cost. Interestingly, one factor that could greatly affect the design choice of the cycle configuration which may not have been explored extensively in many literatures reviewed is the choice of the working fluid. This paper presents a technical analysis on the effect of working fluid on selection of the cycle arrangement for a Generation IV nuclear power plant. It provides insight on potential performance gains that justifies the benefit for an additional cost of a complex cycle, and how the working fluid can influence this choice. The study identifies candidate working fluid that may be suitable for simple, inter-cooled-recuperated, recuperated and other complex cycles. The results obtained shows that for fluid like carbon dioxide, its optimal performance is achieved above it critical points which will require pressurizing the system or operating at high pressure ratio, hence, it would be suitable for a re-compressed inter-cooled cycle configuration. Similar, for fluid like helium with low molecular weight and high gas properties, the simple cycle configuration seem more realistic for its highest cycle efficiency of $41 \%$ and turbomachinery design.
\end{abstract}

\section{INTRODUCTION}

In the last two decades, there has been growing efforts in research and development of closed-cycle gas turbine technology design and operations for the Generation IV nuclear power plant system (Osigwe, Gad-Briggs, Nikoliadis, et al. 2018; Frutschi 2005). Thus, this has led to various pilot cycle configurations, component designs, performance testing, and feasibility demonstration with different working fluid. The design choice for performance operating cycles based on the physical layout or configuration of the closed-cycle gas turbine power plant is driven by the thermo-economic analysis of the system so as to get the right balance between thermal efficiency and capital cost (Osigwe 2018). Interestingly, one factor that could influence the design choice of the cycle configuration which may not have been explored extensively in many literatures cited is the choice of the working fluid.

Due to the self-containing nature of the closed-cycle gas turbine, almost all permanent gaseous working fluid can be utilized, since the fluid will be operated in the gaseous region beyond its critical temperature all through the cycle (Lee, J. Campbell, and Wright 1981). However, selection of the appropriate working fluid depends on meeting several criteria, some of which are dictated by the special requirements of the existing conversion module. Also, any selected fluid should have an acceptable level of thermal stability at maximum cycle temperature dictated by the heat source temperature. It should not be corrosive to the materials of the machinery and should be readily available at modest cost. Other factors to consider include inflammability and toxicity.

To this end, the closed-cycle gas turbine working fluids commonly employed include the monoatomic inert gases and mixtures thereof, as well as air and nitrogen. Thus, many studies have been carried out exploring the potentials of several gaseous working fluids in specific cycle arrangement. El-Genk and Tournier (El-genk and Tournier 2009) analyzed the cycle thermodynamic performance and turbomachinery design of helium and its binary mixtures such as helium-xenon, and helium-nitrogen for a very 
high-temperature gas reactor plant coupled with the closed-cycle gas turbine. The study showed that cycle with pure helium have better cycle performance, however, the use of binary mixtures have a significant impact on the turbomachinery design in terms number of stages and length of the shaft. In another analysis, El-Genk and Tournier (El-Genk and Tournier 2009) investigated the effect of helium and its mixtures on the turbomachinery shaft speed and size. In the work of Gronchiwa (Grochowina 2011), cycle performance was compared for helium and supercritical carbon dioxide using different cycle configuration for a generation IV nuclear power plant. Similarly, Wang and Gu (Wang and $\mathrm{Gu}$ 2005) presented a comparative study of helium, nitrogen, and air for a direct, and indirectly coupled high-temperature gas reactor, and the results showed variation in cycle performance for the different fluid with helium having more favourable outcome. Najjar and Zammout (Yousef and Zaamout 1992) also carried out a cycle performance comparative study using combustion gases, helium, and air for a recuperated closed-cycle gas turbine. Lee et al., (Lee, J. Campbell, and Wright 1981) analyzed the effect of thermodynamic and transport properties of different gases at fixed pressure ratio factor, for optimum selection of a coal-fired closed-cycle gas turbine design.

For fluid like carbon dioxide, Kato et al (Kato, Nitawaki, and Muto 2004) presented a performance and design analysis for medium temperature carbon dioxide gas turbine reactor, comparing the influence of intercoolers on the cycle performance for a nuclear reactor. Olumayegun et al. (Olumayegun, Wang, and Kelsall 2017) presented a preliminary study of nitrogen cycle performance and component design for a sodium fast reactor comparing the single and dual shaft arrangements. Ulizar and Pilidis (Ulizar and Pilidis 2000), described the possibility of handling a semi-closed-cycle gas turbine with carbon dioxide and argon. Alpy et al (Alpy et al. 2011) compared gas testing for nitrogen and carbon dioxide in a closed-cycle gas turbine component design prototype. Other researches that have explored several options of working fluid for closed cycle gas turbine technology are documented in references (Invernizzi 2017; Osigwe, Gad-Briggs, Nikolaidis, et al. 2018; Yousef and Zaamout 1992; Lee, J. Campbell, and Wright 1981).

Nonetheless, this paper presents a technical analysis on the effect of selected working fluid on selection of the cycle arrangement for a Generation IV nuclear power plant. It provides insight on potential performance gains that justifies the benefit for an additional cost of a complex cycle, and how the working fluid can influence this choice. The study identifies candidate working fluid that may be suitable for simple, inter-cooled-recuperated, recuperated and other complex cycles. The selected working fluids utilized in this study include carbon dioxide, helium, air and nitrogen. The results obtained shows that for fluid like carbon dioxide, its optimal performance is achieved above it critical points which will require pressurizing the system or operating at high pressure ratio, hence, it would be suitable for a re-compressed inter-cooled cycle configuration. Similarly, for fluid like helium with low molecular weight and high gas properties, the simple cycle configuration seems more realistic for its highest cycle efficiency of $41 \%$ and the easy of its turbomachinery design.

\section{CLOSED-CYCLE CONFIGURATIONS}

The closed-cycle gas turbine consists of different components assembled together with each component accomplishing specific thermodynamic process. The physical arrangement of these components to facilitate the successful conversion of the heat supplied from the nuclear reactor or other heat sources is referred as the cycle configuration. Consequently, there are several possible arrangements of the gas turbine component to meet a given performance requirement, however, as previously mentioned the cycles of interest in this paper include the simple cycle, recuperated, intercooled and intercooled recuperated. The simple closed-cycle gas turbine component arrangements usually consist of the cooling heat exchanger and the turbomachinery set, and have been employed in several nuclear power plants. In order to improve the cycle performance in terms of output power or thermal efficiency, the simple cycle arrangement could be modified with additional components such as recuperation, intercooling, reheating, and recompressing as well as other unique configurations. Gad-Briggs et al., (Gad-Briggs and Pilidis 2016) compared the performance and technical advantages of simple and intercooled recuperated for Generation IV reactor power plants. The results showed that intercooled-recuperated cycle had a better cycle performance than the simple cycle arrangement. Similarly, reference (Noblis 2014) compared the performance of a recuperated cycle, recompression and simple cycle arrangement for supercritical carbon dioxide cycle application.

A decision to improve cycle performance using recuperation means that additional heat exchanger will be incorporated to the simple arrangement, in which a portion of the sensible heat in the turbine exhaust is used to preheat the working fluid prior to entering the heat source. This increases the cycle efficiency at every pressure ratio for which recuperation is possible (Decher 1994; Walsh and Fletcher 1998). Similarly, for intercooled cycle, the compressor work and exit temperature are reduced by incorporating a heat exchanger to cool the working fluid before further compression is achieved. This increases the input thermal power with a slight improvement in the cycle efficiency and significant increase in the output power. References (Ishiyama et al. 2008; Noblis 2014) presented an analysis which describes the optimal number intercooling that could be give an optimal cycle performance and the trade-off between the cycle performance with the capital cost of the overall system. On the other hand, reheating the system increases the cycle efficiency and output power by increasing the average temperature of heat addition.

To this end, the goal of this paper is to provide an analysis on how the choice of working fluid could potentially influence the decision on the type of cycle configuration that could be implemented for a nuclear power plant. Apart from the choice of working fluid, other factors that could also affect the design choice of the cycle arrangement include; environmental concerns and technology readiness level for the closed-cycle gas turbine components as it relates it each working fluid, the type of application (land, sea or space), 
and cost implications. It is important to emphasize that the added complexity to the simple plant design, in order to marginally improve the cycle performance may not be felt to be warranted in terms of capital cost, but the long-term operations will recoup the initial investment capital cost. Table 1 provides an overview of criteria for cycle selection on major characteristics of the closed-cycle gas turbine. The narrative presented in Table 1 shows that investment choice for any cycle configuration would entail considering the high efficiency potential, the complexity of physical layout, technology maturity level, the component size, and potential heat sink usage. All of these criteria could be influence by the choice of the working fluid. For example, the simple closed-cycle configuration has simple layout and have been utilized in several nuclear power plant application, hence, it is proven technology and can be easily implemented for any working fluid. However, its efficiency potential, good heat sink usage, component technology readiness level as it relate to each working fluid could also be considered before making a decision.

Table 1 Major Characteristics of cycle selection for closed-cycle gas turbine

\begin{tabular}{llllll}
\hline Comparison & SC & RC & ICR & IC & RH \\
High-efficiency potential & A & G & G & NE & NE \\
Plant layout & S & A & A & A & A \\
Technology Maturity & P & P & P & NP & NP \\
Component size & P & A & A & A & A \\
Future prospect & A & G & G & - & - \\
Potential heat sink usage & VG & G & A & G & VG \\
& & & & & \\
Key: & & & & \\
SC - simple cycle, RC - recuperated cycle, RH - reheat cycle \\
IC - intercooled cycle, ICR - intercooled-recuperated cycle \\
VG - very good \\
G - good \\
A - acceptable \\
P - proven \\
NE - not economical \\
NP - not proven \\
S - simple
\end{tabular}

\section{THERMODYNAMIC ANALYSIS AND CYCLE MODELING}

To accomplish the set objective of this study, the various properties of the selected working fluid where modelled in GT-ACYSS; a performance and preliminary design code developed by the authors for closed-cycle gas turbine simulations, which has been described in reference (Osigwe et al. 2017).

To this end, the overall performance of the power plant is a function the constituent components of the Generation IV nuclear power plant; hence, the authors have given an overview of the thermodynamic equations implemented in GT-ACYSS for the overall performance assessment of the closed-cycle utilized in the case study, which is described as follow:

Turbo-set: This includes the compressor and the turbine. The behavior of the turbo-set is described with dimensionless parameters such as corrected mass flow, corrected speed, pressure ratio, component efficiencies and work functions. These parameters are plotted on graphs with lines of pressure ratio against corrected mass flow for different corrected speed lines and contour lines of constant efficiency. It is essential when expressing these parameters that the properties of the working fluid are taken into consideration, which is expressed as:

$$
C M F=\left(\frac{W \sqrt{\theta}}{\delta} \times \sqrt{\frac{R}{\gamma}}\right), C S=\left(\frac{N}{\sqrt{\theta R \gamma}}\right), C H=\left(\frac{\Delta H}{\sqrt{\theta R \gamma}}\right)
$$

Where,

$$
\theta=\frac{T}{T_{\text {ref }}}, \text { and } \delta=\frac{P}{P_{\text {ref }}}
$$

The compressor exit temperature is given by the expression

$$
T c_{\text {out }}=T c_{\text {in }}+\frac{T c_{\text {in }}}{\eta_{c}}\left[\left(\frac{P c_{\text {out }}}{P c_{\text {in }}}\right)^{\left(\frac{\gamma-1}{\gamma}\right)}-1\right]
$$

The compressor exit pressure is derived from the given pressure ratio as:

$$
P R_{c}=\frac{P c_{\text {out }}}{P c_{\text {in }}}=f(C M F, C S)
$$

The compressor work (CW), is a product of the mass flow, specific heat capacity at constant pressure and the overall temperature rise in the compressor. This is given as:

$$
C W=W C p\left(T c_{\text {out }}-T c_{\text {in }}\right)
$$

Similarly, turbine exit temperature is given by:

$$
T t_{\text {out }}=T t_{\text {in }}-T t_{\text {in }} \eta_{t}\left[1-\left(\frac{P t_{\text {out }}}{P t_{\text {in }}}\right)^{\left(\frac{\gamma-1}{\gamma}\right)}\right]
$$

And turbine work is expressed as:

$$
T W=W C p\left(T t_{\text {out }}-T t_{\text {in }}\right)
$$

The turbine discharge pressure ratio is calculated using Eq (7)

$$
P R_{t}=\frac{P t_{\text {out }}}{P t_{\text {in }}}=P R_{c}\left[\frac{\sum(1-\Delta P)_{H P S}}{\sum(1+\Delta P)_{L P S}}\right]
$$

Heat Exchangers: The heat exchangers which include the recuperator, gas heater and pre-cooler were modeled using the $\varepsilon$-NTU method and a counter-flow shell and tube configuration was assumed. The $\varepsilon$-NTU method was used since the inlet condition (temperature and pressure) of the fluid stream can be easily obtained and simplifies the iteration involved in predicting the performance of the flow arrangement. This method is fully described in reference (Kakac and Liu 2002; Shah and Sekulic 2003). The approach also assumes that the heat exchanger effectiveness is known and the pressure losses are given.

Therefore, the effectiveness of the heat exchanger is the ratio of the actual heat transfer rate to the thermodynamically limited maximum heat transfer rate available in a counter flow arrangement. It is important to note that thermal conductivity of each working fluid was considered as it has impact on the sizing of the exchangers. 


$$
\begin{gathered}
\varepsilon=\frac{Q_{\text {actual }}}{Q_{\max }} \\
=\frac{C_{\text {hot }}\left(T_{\text {hotin }}-T_{\text {hotout }}\right)}{C_{\text {min }}\left(T_{\text {hotin }}-T_{\text {coldin }}\right)} \\
=\frac{C_{\text {cold }}\left(T_{\text {coldout }}-T_{\text {coldin }}\right)}{C_{\text {min }}\left(T_{\text {hotin }}-T_{\text {coldin }}\right)}
\end{gathered}
$$

Where,

$$
\begin{aligned}
C_{\text {min }} & =\left\{\begin{array}{l}
C_{\text {hot }} \text { for } C_{\text {hot }}<C_{\text {cold }} \\
C_{\text {cold }} \text { for } C_{\text {cold }}<C_{\text {hot }}
\end{array}\right. \\
C_{\text {hot }} & =\left(W C_{P}\right) \text { hot fluid Stream } \\
C_{\text {cold }} & =\left(W C_{P}\right) \text { cold fluid Stream }
\end{aligned}
$$

For counter flow shell and tube heat exchangers, number of transfer unit (NTU) is given by:

$$
N T U=\frac{L O G_{e}\left[\frac{2-\varepsilon\left(1+C^{*}-\eta_{H e x}\right.}{2-\varepsilon\left(1+C^{*}+\eta_{H e x}\right.}\right]}{\eta_{H e x}}
$$

Where,

$$
\begin{gathered}
C^{*}=\text { Capacity rate ratio }=\frac{C_{\min }}{C_{\max }} \\
\eta_{\text {Hex }}=\left(C^{* 2}+1\right)^{0.5}
\end{gathered}
$$

The inlet and out pressures of the heat exchangers were calculated from the relative pressure losses given by:

$$
P_{\text {out }}=P_{\text {in }}(1-\Delta P)
$$

Reactor Model: The reactor was modeled as a heat source supplying reactor thermal power at a specified temperature and efficiency. The heat gained is given by:

$$
Q_{g}=W C_{p(\text { gas })} \Delta T
$$

The heat source pressure loss is calculated in a similar way as shown in Eq. (14). The power plant thermodynamic states of temperature and pressure at all components were obtained by solving Eqs. (1) - (15)

Cycle Performance Calculation: The overall plant cycle assessment is represented as shaft output power (SOP), specific output power (SP), and cycle thermal efficiency. These are given by the following equations:

$$
S O P=T W-C W / \eta_{m}
$$

The capacity of the plant is represented as specific power (SP), given by:

$$
S P=S O P / W
$$

The cycle thermal efficiency is given by:

$$
\eta_{t h}=S O P / Q_{g}
$$

Table 2 Baseline Parameter for Parametric Study

\begin{tabular}{ll}
\hline Parameters & Values \\
Compressor mass flow rate (kg/s) & 441 \\
Compressor inlet temperature (K) & 301 \\
Compressor inlet pressure (MPa) & 2.5 \\
Compressor isentropic efficiency (\%) & 85 \\
Turbine entry temperature (K) & 1023 \\
Turbine exit pressure (MPa) & 2.55 \\
Turbine isentropic efficiency (\%) & 85 \\
ReX, IC \& PC effectiveness (\%) & 85 \\
GH effectiveness (\%) & 88 \\
\hline \hline
\end{tabular}

An analytical evaluation of the listed power plant arrangements was done with baseline conditions shown in Table 2. The different configurations were compared for different working fluids (helium, air, carbon dioxide and nitrogen). The studies assumed that the nuclear reactor transfers a fixed heat rate to the working fluids at some specified temperature. The Gen-IV systems applicable to this analysis are the Very High-Temperature Reactors (VHTR) and Gas-cooled Fast Reactors (GFR). Both reactors are high-temperature helium cooled, with core outlet temperatures between $750^{\circ} \mathrm{C}(1023 \mathrm{~K})$ and $950^{\circ} \mathrm{C}(1223 \mathrm{~K})$. The GFRs uses a fast-spectrum core, while the VHTRs utilize graphite moderation in the solid state. During this simulation, component pressure losses were not taken into consideration. For each working fluid, the same values for the turbomachinery and heat exchangers component efficiencies have been assumed as shown in Table 2. The heat source temperature and mass flow was simulated the same for all working fluid and other plant characteristics as shown in Table 2. This is to give a reasonable comparison on the behavior of each selected working used in this analysis. However, in reality the maximum attainable temperature may differ for each working fluid as required by the reactor.

\section{RESULTS AND DISCUSSION}

Performance and Design Considerations: In this session, discussion on the performance potentials and design consideration for each working fluid is presented.

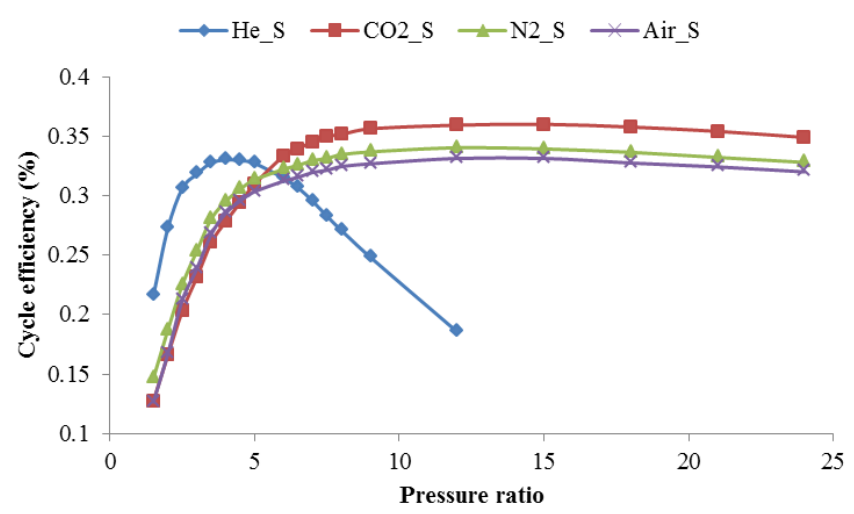

Figure 1 Simple Cycle Configuration efficiency for selected working fluid 


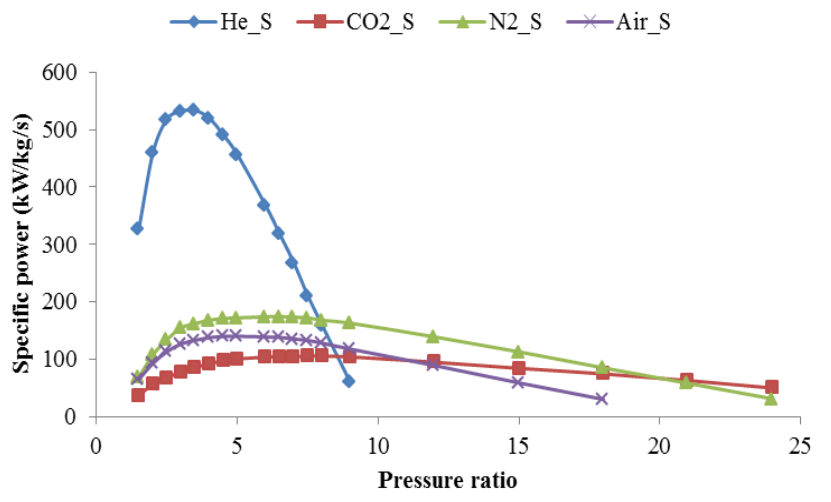

Figure 2 Simple cycle configuration specific power for selected working fluid

Figure (1) - (8) shows the effect of the selected cycle configurations on the overall cycle efficiency at different pressure ratios and for selected working fluids. The simple cycle is the most common form of closed-cycle configuration and offers the least efficiency at low-pressure ratios for most non-inert gases. For this cycle, the efficiency increases as the pressure ratio increases until it reaches a maximum at some pressure ratio for a fixed TET. The simulation results show that the simple cycle efficiencies for the different working fluids peaked at $36.05 \%$ for carbon dioxide at a pressure ratio of $15: 1,34.07 \%$ for nitrogen at pressure ratio of $12: 1,33.5 \%$ for air at pressure ratio of $12: 1$ and $33.2 \%$ for helium at pressure ratio of $4: 1$. To achieve the above optimum efficiencies at the specified optimum pressure ratios for a simple cycle would result in high number of compressor and turbine stages. Similarly, the specific power peaks at pressure ratios of 9 for carbon dioxide at $105.5 \mathrm{~kW} / \mathrm{kgs}, 7: 1$ for nitrogen at $174.32 \mathrm{~kW} / \mathrm{kgs}, 7: 1$ for air at $138 \mathrm{~kW} / \mathrm{kgs}$, and 4:1 for helium at $533.5 \mathrm{~kW} / \mathrm{kgs}$.

From this result, a pressure ratio of 4 for helium fluid could seem a bit high due to the complex nature of its turbomachinery design. However, due to the simple layout of this cycle configuration, and its usage in several applications, adapting it for helium could be easily achieved when compared with other cycle configuration. One could say that this could also be applicable to other fluids like carbon dioxide. On the contrary, the optimum pressure for carbon dioxide is 15; hence, this could have design and cost implications.

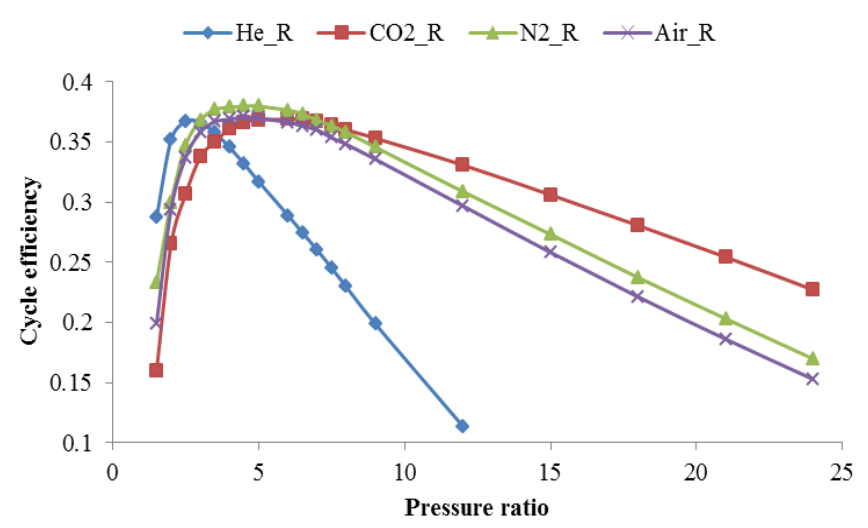

Figure 3 Recuperated cycle configuration efficiency for selected working fluid

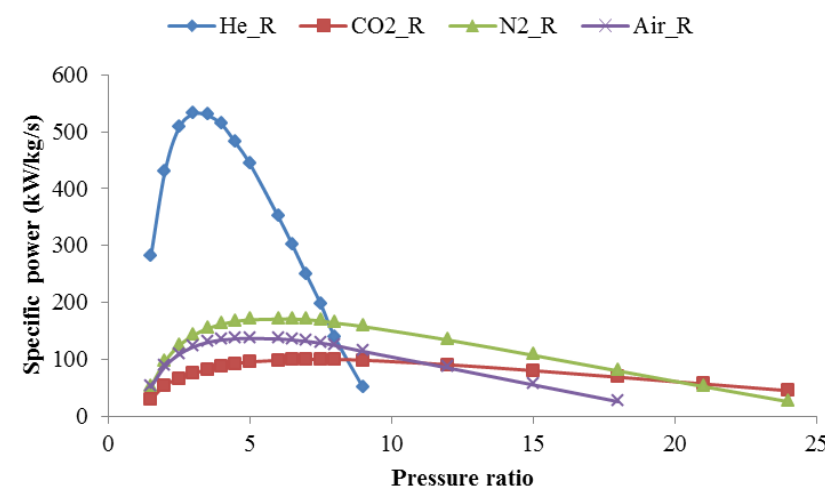

Figure 4 Recuperated cycle configuration specific power for selected working fluid

Introducing a recuperator offered a better cycle efficiency at lower pressure ratios for all working fluids. This is because of the utilization of the waste heat extracted from the turbine discharge temperature to preheat the working fluid prior to entering the gas heater, thus allowing more working fluid to pass through and increasing the overall efficiency at every pressure ratio for which recuperation is possible. The recuperated cycle shows a maximum in cycle efficiency that occurred at a much lower pressure ratio than the simple cycle. The low-pressure ratio can be of benefit in the reduction of the turbo-set sizes which means a great reduction in the overall cost of turbo-set especially for helium. Unlike the simple cycle as the pressure ratio increases beyond it maximum efficiency, the need for recuperation becomes irrelevant. This is because the temperature difference between the turbine exit and compressor discharge approaches zero. The simulated results of the recuperated cycle in fig. 3 and 4 show a maximum cycle efficiency of $38.2 \%$ for carbon dioxide at a pressure ratio of $6.5: 1,37.96 \%$ for nitrogen at a pressure ratio of $4.5: 1,37.06 \%$ for air at a pressure ratio of $4.5: 1$, and $36.74 \%$ for helium at a pressure ratio of 2.5:1. The specific power for the recuperated cycle was slightly lower than that of the simple cycle. This is due to a slight increase in the turbine discharge temperature, which reduces the turbine work. Similarly, for the recuperated cycle, the specific power peaked at pressure ratios of 9 for carbon dioxide at $101.6 \mathrm{~kW} / \mathrm{kgs}, 7: 1$ for nitrogen at $171.22 \mathrm{~kW} / \mathrm{kgs}$, $7: 1$ for air at $136.97 \mathrm{~kW} / \mathrm{kgs}$, and $4: 1$ for helium at 531.5 $\mathrm{kW} / \mathrm{kgs}$. It is important to mention that the benefit of using recuperation will be at an additional initial cost incurred for the heat exchanger. However, this additional capital cost could be offset during the plant long term operation.

One advantage of the recuperated cycle configuration is that it is has also been used in several nuclear plants, hence, one could say that this technology could be easily adapted for each working fluid used in this study. For helium, the recuperated cycle could be seen as one of the most suitable configuration, since the goal of a reduced pressure ratio at improved cycle efficiency could be easily achieved. 


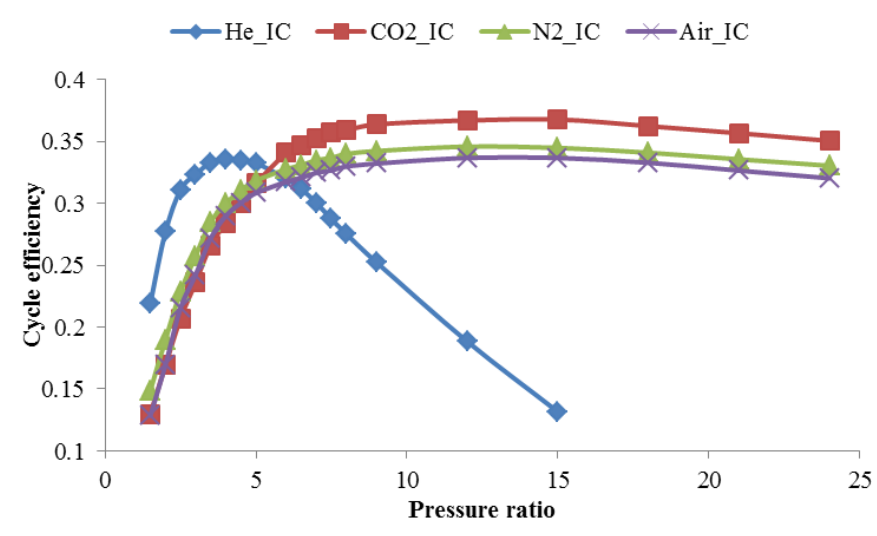

Figure 5 Inter-cooled cycle configuration efficiency for selected working fluid

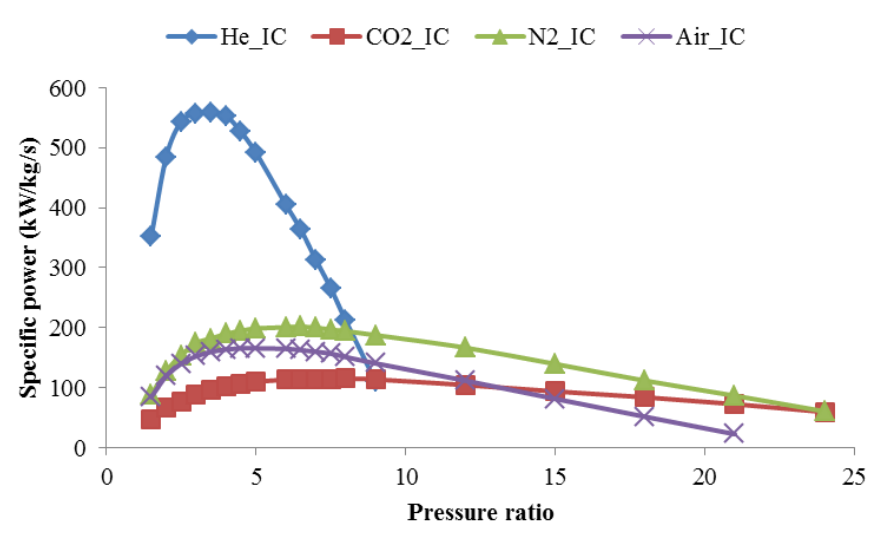

Figure 6 Inter-cooled cycle configuration specific power for selected working fluid

The decision whether to incorporate an intercooler to the simple cycle is important to the thermodynamic cycle since it affects both the plant layout and heat rejection characteristics. Thus, introducing an intercooler reduces the total compressor work and improves the net output work. To evaluate the intercooled cycle (IC), the component efficiencies and pressure ratios in both compressors were assumed to be the same and equal to $\sqrt{P R}$. The cycle produces between $15 \%$ and $25 \%$ increase in output power which is reflected in the specific power as shown fig. 5 and 6 . Intercooling offers a slight advantage in cycle efficiency (between $1.5 \%$ and $2.5 \%$ ) compared with the simple cycle configuration. This is because it gives a lower compressor discharge temperature for the same pressure ratio as the simple cycle. Hence, the pressure ratio at which the compressor discharge temperature will become equal to the turbine discharge temperature is higher than that of simple cycle arrangement, which increases cycle peak pressure ratio (the point where maximum efficiency is obtained). However, this efficiency gain must be weighed against power plant complexity and differing heat rejection temperature based on the working fluid utilized.

Nonetheless, from the results shown, the maximum efficiency for each working fluid used in this study are as follow; $33.9 \%$ for helium, $36.42 \%$ for carbon dioxide,
$34.53 \%$ for nitrogen and $33.8 \%$. The results also show that the major benefit of inter-cooling is the increased output power, which could be beneficial for fluid like carbon dioxide, nitrogen and air with low heat capability compared with helium.

An intercooled cycle has been shown to be well suited for district heating (Frutschi 2005; Osigwe 2018). When considering the benefit of district heat, one could arguably suggest that using helium as working fluid could be more beneficial in terms of compact heat exchangers, when compared with other fluid. In this circumstance, helium could be the appropriate working fluid, but there must be a reasonable compromise in terms of the operational cost since helium is an expensive working fluid. One of the constrained to using the intercooled cycle configuration could be associated with the gas turbine component technology readiness level. For fluid like air and nitrogen, this may not be much a hassle, but for helium and carbon dioxide this must be put into considerations.

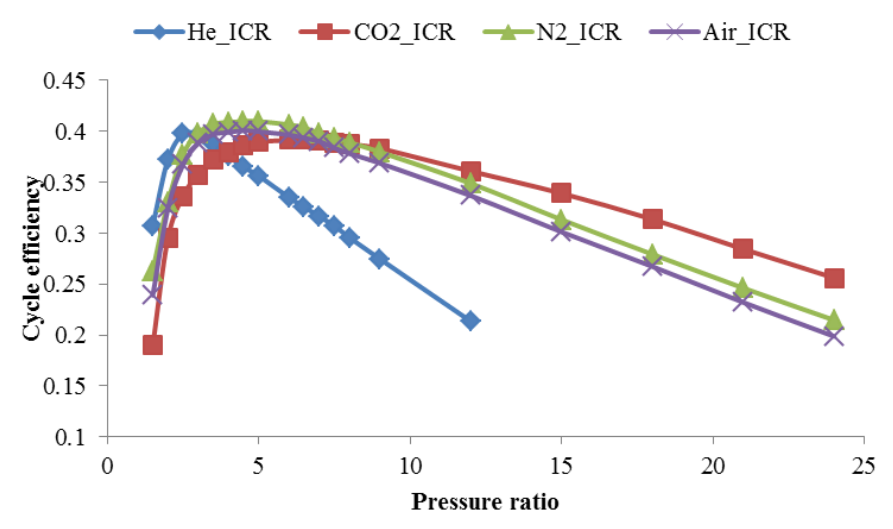

Figure 7 Inter-cooled recuperated cycle configuration efficiency for selected working fluid

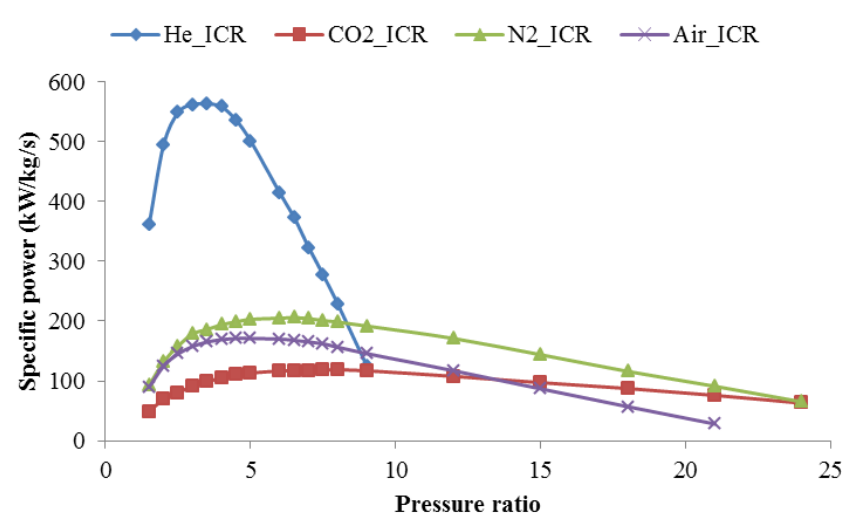

Figure 8 Inter-cooled recuperated cycle configuration specific power for selected working fluid

A combination of intercooling and recuperation offers an optimal cycle performance. This is because; each new component added improves key cycle performance indicators. In this case, the intercooler increases the output power, while the recuperation provides an increase in the cycle efficiency as indicated in figs 7 and 8 . This also implies that the maximum cycle efficiency occurs at lower pressure ratios, as 
compared with the simple cycle. The intercooled-recuperated cycle (ICR) improves the cycle efficiency between $10 \%$ and $15 \%$. However, this extra benefit comes with an extra capital cost for the additional components.

Similar to the inter-cooled cycle configuration, the ICR is an emerging cycle configuration for nuclear power plants. In the last 10 years, there has been growing research and development on the use ICR. This is suitable for any fluid of choice, especially for carbon dioxide and helium which have the least component design technology readiness level compared to air and nitrogen. From design point view, the implication of the cycle configuration analysis on cycle efficiency and specific power set a reasonable compromise in terms of plant size, cost (capital and operational cost), and turbo-set and heat exchanger design challenges for the ICR closed-cycle gas turbine.

\section{Risk Consideration:}

The aerodynamic and mechanical design for turbo-components that use air as working fluid is widely proven and its configuration for any application whether axial, centrifugal or radial can be easily implemented. This makes the use of air as working fluid for closed-cycle gas turbine design of less risk when compared with other fluids used in this study, because its technology readiness level (TRL) is at an advance level (can be put at 9) and many designers as well as operators are very familiar with the design and operational challenges of turbo-sets which uses air as working fluid. Thus, further, improvement to suit any design specification or optimum decision indicators could be easily initiated.

Although one may say that the basic aerodynamic design principles used for air turbo-set could be applicable to helium, carbon dioxide, nitrogen and any other selected fluid, however, it is important to recognize that the thermodynamic properties of these working fluids are different from that of air which could seemly pose a unique design and operational challenges as to applying them in specified cycle configurations. For helium, its high specific heat capacity and low molecular weight would make its aerodynamic design more complex for cycle configurations with multiple turbo-sets (like inter-cooled recuperated design). Also, considering the fact that helium turbo-sets are not readily available in terms of design and operational experience, it could potentially be a risk factor to consider. To collaborate this argument for helium as documented in references (Frutschi 2005; Osigwe, Gad-Briggs, Nikolaidis, et al. 2018), it becomes obvious that there is still limited design and operational experience in the use of helium turbo-sets for closed-cycle gas turbine application. Hence, a simple cycle or simple recuperated cycle configuration could be an ideal cycle choice since it can be easily achieved or be more realistic to offer high performance at reasonable cost and risk. Although in the last one (1) decade there have been a growing number of researches and development in use of helium for high temperature and very high-temperature closed-cycle gas turbine application, this does not still put the TRL of helium turbo-sets above level 7. Thus, the technology risk for helium turbo-sets will be higher than air.

For carbon dioxide turbo-set, not until the 1990s when supercritical carbon dioxide power cycles started to gain relevance, there has not been any closed-cycle gas turbine power plant project in operation that uses carbon dioxide turbo-sets, apart from the Feher module in 1976 which was experimental (Hoffmann and Feher 1971). Most application of the carbon dioxide turbo-set design is still at the preliminary or laboratory test stage (Frutschi 2005; Osigwe 2018). Thus, the risk level for carbon dioxide turbo-set will be higher compared with helium or air because of it limited design and operational experience in closed-cycle gas turbine application. This could have an additional effect on investment decision for a closed-cycle gas turbine with carbon dioxide as a design choice. The carbon dioxide TRL can be put at below 5 which put it at great risk.

For nitrogen, its thermodynamic behaviour at different temperature and pressure is similar to that of air, which makes its aerodynamic and mechanical design easy to adapt and implement for the closed-cycle gas turbine power plant application. Also, there have been some experimented and built power plant operating with nitrogen turbo-set, although this is not as popular to compare to the use of air or helium. From the author's view, adapting nitrogen turbo-set for closed-cycle gas turbine application may pose less risk compared with helium, and carbon dioxide. This is because of its unique similarity with air, hence, the possibility of having similar or familiar operational challenges.

\section{CONCLUSIONS}

The overarching results and discussion can be concluded as follow:

- The choice of working fluid to a reasonable extent affects the design choice cycle configuration. It sets a reasonable compromise in terms of plant size, cost (capital and operational cost), and turbo-set design challenges. For fluid like carbon dioxide, its optimal performance is achieved above it critical points which will mean pressurizing the system or operating at a very high-pressure ratio for a simple cycle configuration. However cycles with high-pressure ratios tend to pose extra challenges in terms of component design, especially when used for simple cycle layout or configurations that has not previously proven (plants in operation). For this reason, a configuration with intercooling (IC or ICR) which allows for recompression of carbon dioxide seem to be competitive in terms of achieving reasonable performance by splitting the pressure ratio in two compression. For fluid like helium with low molecular weight and high gas properties ( $\gamma$ and $\mathrm{Cp}$ ), the simple or recuperated cycle configuration may seem more realistic due to its thermodynamic and heat properties which could have effect on design issues. Other factors that may influence the design choice selection of cycle configuration include: application (land-based, sea-based, space-based), proven component design and operation (technology readiness for each component related to the working fluid), reliability, maintainability, cooling medium of the nuclear reactor, overall nuclear plant layout, the potential for energy utilization and sustainability, working fluid 
management and cost. These factors could give a reasonable justification for the configuration that is most suitable for each working fluid.

- Cycle efficiency potential for each working fluid is greatest for working fluid with a higher ratio of specific heat at low-pressure ratio and least ratio of specific heat at higher pressure ratio. Since the specific heat ratio of helium is larger than, air, nitrogen and carbon dioxide the optimum efficiency for helium occur at the lowest pressure ratio compared with other fluids. However, the decision for suitable cycle configuration is not only hinged on the fluid cycle efficiency potential. Other factors has to been taken into considerations.

\section{NOMENCLATURE}

\begin{tabular}{|c|c|}
\hline$C$ & corrosion allowance \\
\hline$C p$ & specific heat at constant pressure \\
\hline$C v$ & specific heat at constant volume \\
\hline $\mathrm{CH}$ & corrected enthalpy \\
\hline$C M F$ & corrected mass flow \\
\hline$C S$ & corrected speed \\
\hline$C W$ & compressor work \\
\hline$G H$ & gas heater \\
\hline$G T$ & gas turbine \\
\hline$H$ & enthalpy $(\mathrm{J} / \mathrm{kgK})$ \\
\hline Hex & heat exchanger \\
\hline$H P C$ & high pressure compressor \\
\hline$H P S$ & high pressure side \\
\hline$H S T$ & heat source temperature (reactor) \\
\hline$I C$ & inter-cooler \\
\hline$I C R$ & inter-cooler recuperation \\
\hline$L P C$ & low pressure compressor \\
\hline$L P S$ & low pressure side \\
\hline$N$ & rotational speed (rpm) \\
\hline$N T U$ & number of transfer unit \\
\hline$P$ & pressure $(\mathrm{Pa})$ \\
\hline$P C$ & pre-cooler \\
\hline$P R$ & pressure ratio \\
\hline$Q_{\text {actual }}$ & heat transfer \\
\hline$Q_{g}$ & heat supplied from the reactor \\
\hline$R$ & specific gas constant $(\mathrm{J} / \mathrm{kgK})$ \\
\hline $\operatorname{ReX}$ & recuperator \\
\hline$S O P$ & shaft output power \\
\hline$T$ & temperature $(K)$ \\
\hline TET & turbine entry temperature $(K)$ \\
\hline$T W$ & turbine work \\
\hline$V$ & velocity $(\mathrm{m} / \mathrm{s}))$ \\
\hline$W$ & mass flow $(\mathrm{kg} / \mathrm{s})$ \\
\hline
\end{tabular}

\section{Greek letters}

$\begin{array}{ll}\rho & \text { density }\left(\mathrm{kg} / \mathrm{m}^{3}\right) \\ \gamma & \text { ratio of specific heats } \\ \delta & \text { referred pressure parameter } \\ \theta & \text { referred temperature parameter } \\ \eta & \text { efficiency } \\ \varepsilon & \text { effectiveness } \\ \Delta & \text { difference }\end{array}$

\begin{tabular}{ll}
\multicolumn{2}{l}{ Subscripts } \\
$c$ & compressor \\
cin & compressor inlet \\
cout & compressor outlet \\
$m$ & mechanical \\
$t$ & turbine \\
th & thermal \\
tin & turbine in \\
tout & turbine out
\end{tabular}

\section{REFERENCES}

Alpy, N, L Cachon, D. Haubensack, J. Floyd, N. Simon, L. Gicquel, G. Rodriguez, M. Saez, and G. Laffont. 2011. "Gas Cycle Testing Opportunity with ASTRID, the French SFR Prototype." In Proceedings of Supercritical CO2 Power Cycle Symposium, 42-51. Boulder, Colorado.

Decher, R. 1994. Energy Coversion: Systems, Flow Physics and Engineering. New York: Oxford University Press.

El-Genk, M. S., and J Tournier. 2009. "Effects of Working Fluid and Shaft Rotation Speed on the Performance of HTR Plants and the Size of CBC Turbo-Machine." Nuclear Engineering and Design 239: 1811-27.

El-genk, Mohamed S, and Jean-michel Tournier. 2009. "Performance Analyses of VHTR Plants with Direct and Indirect Closed Brayton Cycles and Different Working Fluids." Progress in Nuclear Energy 51: 556-72. doi:10.1016/j.pnucene.2008.11.004.

Frutschi, H U. 2005. Closed-Cycle Gas Turbines: Operating Experience and Future Potential. 1st ed. New York: ASME.

Gad-Briggs, A, and P Pilidis. 2016. "Analyses of Simple and Intercooled Recuperated Direct Brayton Helium Gas Turbine Cycles for Generation IV Reactor Power Plants." ASME Journal of Nuclear Engineering and Radiation Science 3: 011017-1-011017-7. doi:10:1115/1.4033398.

Grochowina, Filip. 2011. "Performance Evaluation of Gas Turbines for Nuclear Power Plants." Cranfield University.

Hoffmann, J. R., and E. G Feher. 1971. "150 KWe Supercritical Closed-Cycle System." Transactions of the ASME 93 (1): 70-80.

Invernizzi, C. M. 2017. "Prospects of Mixtures as Working Fluids in Real-Gas Brayton Cycles.” Energies 10: 115. doi:10.3390/en10101649.

Ishiyama, S, Y Muto, Y Kato, S Nishio, T Hayashi, and Y Nomoto. 2008. "Study of Steam, Helium, and Supercritical CO2 Turbine Power Generations in Prototype Fusion Power Reactor." Nuclear Energy 50: 325-32.

Kakac, S, and H Liu. 2002. Heat Exchangers Selection, Rating and Therrmal Design. 2nd ed. New York: CPC Press.

Kato, Y, T Nitawaki, and Y Muto. 2004. "Medium Temperature Carbon Dioxide Gas Turbine Reactor." Nuclear Engineering and Design 230: 195-207.

Lee, J C, Jr J. Campbell, and D E Wright. 1981. "Closed-Cycle Gas Turbine Working Fluids." 
Transactions of the ASME Vol. 103: 220-28.

Noblis, C. W. 2014. "Analysis of Brayton Cycles Utilizing Supercritical Carbon Dioxide." New York.

Olumayegun, O., M. Wang, and G. Kelsall. 2017. "Thermodynamic Analysis and Preliminary Design of Closed Brayton Cycle Using Nitrogen as Working Fluid and Coupled to Small Modular Sodium-Cooled Fast Reactor (SM-SFR)." Applied Energy 191: 43653.

Osigwe, E. O. 2018. "Techno-Economic and Risk Analysis of Closed-Cycle Gas Turbine Systems for Sustainable Energy Conversion." Cranfield University.

Osigwe, E. O., A Gad-Briggs, T Nikoliadis, P. Pilidis, and S. Sampath. 2018. "Performance Analysis of Generation IV Nuclear Reactor Power Plant Using CO2 AND N2: Case Study of a Recuperated Brayton Gas Turbine Cycle." In Proceedings of the 2018 26th International Conference on Nuclear Engineering. London: ASME.

Osigwe, E. O, A Gad-Briggs, T Nikolaidis, P. Pilidis, and S. Sampath. 2018. "Multi-Fluid Gas Turbine Components Scaling for a Generation IV Nuclear Power Plant Performance Simulation." Cranfield.

Osigwe, E. O, P Pilidis, T Nikoliadis, and S Sampath. 2017. "GT-ACYSS: Gas Turbine Arekret-Cycle Simulation
Tool for Training and Educational Purposes." Cranfield.

Shah, R. K, and D.P Sekulic. 2003. Fundamentals of Heat Exchanger Design. New Jersey: John Wiley \& Sons, Inc.

Ulizar, I., and P. Pilidis. 2000. "Handling of Semiclosed Cycle Gas Turbine with a Carbon Dioxide-Argon Working Fluid." ASME 122: 437-41.

Walsh, P.P., and P. Fletcher. 1998. Gas Turbine Performance. Second. Oxford: Blackwell Science.

Wang, Jie, and Yihua Gu. 2005. "Parametric Studies on Different Gas Turbine Cycles for a High Temperature Gas-Cooled Reactor" 235: 1761-72. doi:10.1016/j.nucengdes.2005.02.007.

Yousef, S. H., and M. S Zaamout. 1992. "Comparative Performance of Closed Cycle Gas Turbine Engine with Heat Recovery Using Different Gases." Heat Recovery Systems and CHP 12 (6). doi:10.1016/0890-4332(92)90017-C. 


\section{Effect of working fluid on selection of gas turbine cycle configuration for Gen-IV nuclear power plant system}

Osigwe, Emmanuel O.

JSME

Osigwe EO, Gad-Briggs A, Pilidis P, Nikolaidis T \& Sampath S, Effect of working fluid on selection of gas turbine cycle configuration for Gen-IV nuclear power plant system. In:

ICONE-27: 27th International Conference on Nuclear Engineering, Ibaraki, Japan, 19-24 May 2019.

https://dspace.lib.cranfield.ac.uk/handle/1826/14653

Downloaded from Cranfield Library Services E-Repository 